\title{
Household food insecurity is associated with depressive symptoms: results from a Mexican population-based survey
}

\author{
Spyros Kolovos $^{1} \cdot$ Gerardo A Zavala $^{2,3}$ (D) Anne Sophie Leijen ${ }^{2} \cdot$ Hugo Melgar-Quiñonez ${ }^{4} \cdot$ Maurits van Tulder $^{2}$
}

Received: 31 July 2018 / Accepted: 24 January 2020 / Published online: 31 January 2020

(C) The Author(s) 2020

\begin{abstract}
The objective of this cross-sectional study was to assess the relationship between food insecurity and depression in the Mexican population. We used data from the 2012 health and nutrition survey (ENSANUT), which is representative of the Mexican population. Food insecurity was determined by the Latin American and Caribbean Food Security Scale (ELCSA). Depressive symptoms were evaluated using the Center for Epidemiological Studies Depression Scale Short-Form (CES-D-SF). Adjusted logistic regression analyses and ANCOVA were used. Out of 33,011 participants, 5788 (18\%) had high depressive symptoms and 24,098 (73\%) experienced food insecurity. The adjusted logistic regression analysis showed that, participants with mild food insecurity, $(\mathrm{OR}=1.47,95 \% \mathrm{CI}=1.27$ to 1.71$)$, moderate food insecurity $(\mathrm{OR}=2.14,95 \% \mathrm{CI}=1.85$ to 2.47$)$ and severe food insecurity ( $\mathrm{OR}=3.01,95 \% \mathrm{CI}=2.51$ to 3.60 , ) were more likely to have high depressive symptoms than food secure participants. Participants with moderate food insecurity $(\mathrm{OR}=1.45,95 \% \mathrm{CI}=1.28$ to 1.64$)$ and severe food insecurity $(\mathrm{OR}=2.04,95 \% \mathrm{CI}=$ 1.76 to 2.37 ) were more likely to suffer from depression as compared to participants with mild food insecurity. Participants with severe food insecurity were more likely $(\mathrm{OR}=1.41,95 \% \mathrm{CI}=1.21$ to 1.65$)$ to suffer from depression compared to participants with moderate food insecurity. This paper provides an overview of the complex problem of food insecurity and mental health. Despite the unknown causality, the analysis suggests a strong association between depression and food insecurity. This problem calls for much more attention from the scientific community. Given the high prevalence of depression and the high prevalence of household food insecurity in Mexico, the implementation of successful public health programs to improve food security is necessary.
\end{abstract}

Keywords Depression · Food insecurity · ENSANUT $2012 \cdot$ Mexico

Spyros Kolovos and Gerardo A Zavala contributed equally to this work.

Electronic supplementary material The online version of this article (https://doi.org/10.1007/s12571-020-01014-1) contains supplementary material, which is available to authorized users.

Gerardo A Zavala

gzavala@gmail.com

$1 \quad$ Nuffield Department of Orthopaedics, Rheumatology and Musculoskeletal Sciences, University of Oxford, Oxford, UK

2 Department of Health Sciences, Vrije Universiteit, Amsterdam, Netherlands

3 Department of Health Sciences, University of York, York, UK

4 School of Human Nutrition, McGill University, Quebec, Canada

\section{Introduction}

Depression, one of the leading causes of disability worldwide (Vos et al. 2016; Kassebaum et al. 2016), is related to large healthcare and societal costs due to increased healthcare utilization and productivity losses (Olesen et al. 2012; Wittchen et al. 2011). Depression is also associated with deterioration in health-related Quality-of-Life (QoL) and impairments are found in mental, physical, and social functioning of individuals (IsHak et al. 2011; Berlim and Fleck 2007; Kolovos et al. 2017). Similar to global prevalence rates (12-month prevalence 5.2\%), depression is common in Mexico with a 12month prevalence of $6.1 \%$ and a lifetime prevalence of 12.8\% (Hasin et al. 2005; Slone et al. 2006). The impact of depression on the Mexican population has increased between 1990 and 2013, from 781 Years Lived with Disabilities (YLDS) in 1990 for the total population to 1259 YLDS in 2013, and depression is ranked among the 10 leading causes 
of disability in the country (Charlson et al. 2015). Depression often occurs in conjunction with other debilitating conditions, such as, type II diabetes, cardiovascular disease and obesity (Kupfer and Frank 2003; G. A. Zavala et al. 2018a; Mendenhall et al. 2017).

Household food insecurity is defined as a lack of physical and economic access to food for all members of the household at all times (Maxwell 1996). Food should be of adequate quality and thus meeting the dietary needs and preferences for a healthy lifestyle (Maxwell 1996). Food security is often categorized into mild, moderate and severe (Romo-Aviles and Ortiz-Hernández 2018). As a multidimensional concept, household food insecurity has also a social aspect, which includes food availability, affordability and the culturally accepted means of acquiring food for the household (Jones et al. 2013; Trefry et al. 2014). So far, household food insecurity has been related to obesity, systemic inflammation, and diabetes in adults, and stunting, lower quality of life and delayed development in children (Rose-Jacobs et al. 2008; Seligman et al. 2010). Therefore, household food insecurity is considered a major health and societal challenge worldwide (Alarcão et al. 2020).

Previous studies including pregnant women in the United Kingdom (UK) and adults in Canada have linked household food insecurity and mental health (Tarasuk et al. 2013; Power et al. 2017). In a recent study, household food insecurity has been associated with poorer mental health across many regions globally (Jones 2017). However, this study only considered household food insecurity experience and the negative experience index (an instrument that assesses subjective feelings of well-being and ill-being) as a proxy for depression ( $\mathrm{Li}$ et al. 2013). Furthermore, the focus of the study was on pooled outcomes from different countries and not on country-specific estimates (Friedenreich 1993). Studies conducted in Canada, Australia, the USA, and Sub-Saharan Africa found that household food insecurity is linked to mental health problems (Che \& Chen, 2001; Dewing, Tomlinson, le Roux, Chopra, \& Tsai, 2013; Fuller-Thomson \& Nimigon, 2008; Hadley \& Patil, 2006; Stuff et al., 2004). The available information addressing this issue in Latin American countries is still limited.

Household food insecurity has been associated in Mexico with negative health outcomes such as anaemia, obesity, diabetes and hypertension (Pérez-Escamilla et al. 2014; Fischer et al. 2014; Morales-Ruan Mdel et al. 2014). However, information concerning the association of food insecurity with mental health is lacking. The prevalence of both food insecurity and depression in Mexico warrants the assessment of their association (Sharma and Gulati 2015). The aims of the current study were to examine: 1) if household food insecurity is associated with depression; 2) if the risk of suffering from depression differs between the different severity categories of household food insecurity. We hypothesized that individuals with household food insecurity will have higher odds of suffering from depression compared to food secure individuals.

\section{Materials and methods}

\subsection{Study design and population}

Data concerning household food insecurity, depressive symptoms and participants' demographics characteristics were extracted from the 2012 Mexican National Health and Nutrition Survey (ENSANUT) (Gutierrez et al. 2012). ENSANUT is performed by the National Institute of Public Health and the Ministry of Health of Mexico. ENSASUT is a nationally representative, probabilistic multistage stratified cluster survey representative of the Mexican population at national, state and municipality levels. When possible, a member from each age group, 5 to 9 years, 10 to 19 and more than 20 years, was randomly selected from each household. Sampling weights are used to estimate nationally representative values. A more detailed description of the sampling procedures and survey methodology has been described elsewhere (RomeroMartínez et al. 2013). Data were collected from October 2011 to May 2012. This survey was applied to 50,528 households (89,000 participants), with a response rate of $87 \%$. In the present study, we selected participants if they were over 19 years of age.

All participants signed an informed consent before answering questions and the survey was approved by the ethics committee of the National Institute of Public Health (Barquera et al. 2013). Additional information about methodology can be found elsewhere (Gutierrez et al. 2012). Our study was reported according to the STROBE Statement.

\subsection{Assessment of depression}

Depressive symptom severity was measured with the Center for Epidemiological Studies Depression scale short-form (CESD-SF), which is a self-report unidimensional and reliable questionnaire used to evaluate depression severity over the last two weeks (Levine 2013). The CESD-SF consists of 7 items that are scored on a 0 to 3 Likert scale $(0=$ rarely or none of the time, $1=$ some or few of the times, $2=$ occasionally or a moderate fraction of time and $3=$ all of the time). The total score on this scale ranges from 0 to 21 ; higher scores indicate more severe depressive symptoms. A cut-off score of $\geq 8$ along this scale was shown to be a satisfactory threshold in a previous study including 8858 participants, with acceptable specificity and modest sensitivity for classifying individuals at risk for major depressive disorder (Levine 2013). The same cut-off was used in the current study to categorize participants as suffering from at least mild depressive symptoms (reported as depression hereafter). Participants with a CESD-SF score of 
7 or less were considered suffering from minor or no depressive symptoms.

\subsection{Household food insecurity}

Food insecurity was measured at the household level according to the validated Latin American and Caribbean Food Security Scale (ELCSA) specifically developed for the Latin America and Caribbean context (de la ELCSA 2012). This scale includes eight questions regarding poverty-related food insecurity household experiences (for instance being worried about not having access to enough food; going without food for a whole day; or doing things that are not sociably accepted in order to get food) during the three months preceding the survey. This questionnaire was completed by the main household meal preparer. A categorization algorithm has been released by the developers of the questionnaire in order to classify households in the following categories: "food secure household" (score $=0$ ), "mild food insecurity" (score $=1-3$ ), "moderate food insecurity" (score $=4-6$ ), and "severe food insecurity" (score = 7-8) (de la ELCSA 2012).

\subsection{Covariates}

A number of variables that could influence the association between household food insecurity and depression were included in the survey, and were used as covariates. These variables are: measured BMI (body mass index) stratified in four categories (underweight, normal-weight, overweight and obese), gender, age (years), having a partner (yes/no), selfreported history of diabetes (yes/no), self-reported history of hypertension (yes/no), socio-economic level; 'low' 'middle', 'high' (terciles derived from principal component analysis of household construction materials, urban services [water, sanitation, electricity], and household appliances), and education level stratified in three categories 'no education' (i.e. no formal education), 'middle' (i.e. primary or secondary education), 'high' (i.e. more than secondary education).

\subsection{Statistical analysis}

A complex survey design was used, with the "svy" command in Stata (version 14), to account for different participation rates and sampling probabilities, taking in consideration the expansion factor, the stratum, and the primary sampling unit parameters to establish that the results are representative of the Mexican population. Clinical and demographic characteristics of the participants were reported using descriptive statistics.

To answer the first research question (i.e., is household food insecurity is associated with depression?), we performed a logistic regression analysis using the ELCSA categories as independent variable (i.e., with mild, moderate and severe food insecurity as dummy variables) and depression as the dependent binary variable. For the second research question (i.e., does the risk of having depression differ between the different categories of severity of household food insecurity), we performed logistic regression analyses between each category of household food insecurity with the remaining categories and depression as a binary dependent variable. As a second step in both logistic regression models, we added as potential confounders the variables described above. The variables that were included as covariates were also checked as effect modifiers. The odds ratio (OR) were presented with their $95 \%$ confidence intervals (95\% CI), and were considered significant if the $p$ value was lower than 0.05 .

\subsection{Sensitivity analyses}

We conducted a sensitivity analysis in which a cut-off score of $\geq 9$ in CESD-SF was used to categorize participants as having at least mild depressive symptoms. We performed this analysis to examine whether considering a more conservative threshold to detect depression influences our conclusions, because a cut-off score larger than 8 had been previously used, and had been related to higher than expected depression prevalence $(16 \%)$ in Mexico (Gerardo A Zavala et al. 2018b). As a second sensitivity analysis, we performed a analysis of covariance (ANCOVA) including depression score as the dependent variable and household food insecurity categories as the factor adjusting by gender, age, SES, area, hypertension, diabetes, having a partner, and BMI. We performed this analysis to examine if including depression as a continuous outcome had an effect on the results.

\section{Results}

\subsection{Population characteristics}

From the 33,011 participants included in the analyses, 5788 (18\%) had high depressive symptoms. The mean CESD-SF score for all participants considered in the analysis was 3.64 $(\mathrm{SD}=4.55)$, with a mean of $11.93(\mathrm{SD}=3.52)$ for people suffering from high depressive symptoms and a mean of $1.87(\mathrm{SD}=2.17)$ for people with low or no depressive symptoms (Table 1). A total of $27 \%$ of the participants were food secure, whereas $41 \%$ were mildly food insecure, $20 \%$ moderately food insecure, and $12 \%$ severely food insecure. The mean BMI was $28(\mathrm{SD}=5.41), 10 \%$ of the participants had a previous diagnosis of diabetes and $17 \%$ a previous diagnosis of hypertension. The mean age of the participants was 44 years $(\mathrm{SD}=16), 70 \%$ were living with a partner, and $60 \%$ were women. Most of the participants had low or middle socioeconomic status (35\% and 34\% respectively) and $31 \%$ had high socioeconomic status (Table 1). 
Table 1 Characteristics of the study population

\begin{tabular}{|c|c|c|c|}
\hline Characteristic & $\begin{array}{l}\text { Total } \\
(n=33,011)\end{array}$ & $\begin{array}{l}\text { Depression } \\
(n=5788 ; 18 \%)\end{array}$ & $\begin{array}{l}\text { No depression } \\
(n=27,223 ; 82 \%)\end{array}$ \\
\hline Female, $\%$ & 60 & 74 & 56 \\
\hline Age, mean (SD) & $44(16)$ & $47(16)$ & $44(17)$ \\
\hline Living with partner, $\%$ & 70 & 66 & 71 \\
\hline Rural area, \% & 35 & 37 & 35 \\
\hline \multicolumn{4}{|l|}{ Education, \% } \\
\hline Non & 10 & 16 & 9 \\
\hline Middle & 65 & 70 & 64 \\
\hline High & 25 & 14 & 27 \\
\hline \multicolumn{4}{|l|}{ Socioeconomic status, $\%$} \\
\hline Low & 35 & 41 & 35 \\
\hline Middle & 34 & 35 & 33 \\
\hline High & 31 & 24 & 32 \\
\hline BMI, mean (SD) & $28(5.41)$ & $30(5.62)$ & $28(5.35)$ \\
\hline \multicolumn{4}{|l|}{ Household food security categories, $\%$} \\
\hline Secure & 27 & 16 & 29 \\
\hline Mild insecurity & 41 & 37 & 42 \\
\hline Moderate insecurity & 20 & 26 & 19 \\
\hline Severe insecurity & 12 & 21 & 10 \\
\hline CES-D-SF, mean (SD) & $3.64(4.55)$ & $11.93(3.52)$ & $1.87(2.17)$ \\
\hline Previous diabetes diagnosis $\%$ & 10 & 15 & 9 \\
\hline Previous hypertension diagnosis $\%$ & 17 & 25 & 15 \\
\hline
\end{tabular}

$B M I$ Body mass index, $C E S-D-S F$ Center for Epidemiological Studies Depression Short-Form, $S D$, Standard deviation

\subsection{Household food insecurity and depression}

Table 2 shows the results from the crude and adjusted logistic regression models. The adjusted (by gender, age, SES, area, hypertension, diabetes, having a partner and BMI) logistic regression analysis showed that participants with mild food insecurity (Odds Ratio $[\mathrm{OR}]=1.47,95 \% \mathrm{CI}=1.27$ to 1.71 ), moderate food insecurity $(\mathrm{OR}=2.14,95 \% \mathrm{CI}=1.85$ to 2.47 ), and severe food insecurity $(\mathrm{OR}=3.01,95 \% \mathrm{CI}=2.51$ to 3.60$)$ were more likely to suffer from depression than food secure participants.

Some of the covariates were associated with lower risk of depression, in particular, being male, having no history of diabetes or of hypertension. Furthermore, no or intermediate educational level were associated with higher risk for depression compared with high educational level. None of the studied covariates were effect modifiers (i.e., the variables did not change the direction of the association) and thus we did not stratify our analysis.

\subsection{Differences between household food insecurity categories}

We tested whether the likelihood of depression occurrence differs between the different categories of household food insecurity (Table 3). The results indicated that participants with moderate food insecurity $(\mathrm{OR}=1.45,95 \% \mathrm{CI}=1.28$ to 1.64) and severe food insecurity $(\mathrm{OR}=2.04,95 \% \mathrm{CI}=1.76$ to 2.37) were more likely to suffer from depression as compared to participants with mild food insecurity. Furthermore, participants with severe food insecurity were more likely $(\mathrm{OR}=1.41,95 \% \mathrm{CI}=1.21$ to 1.65$)$ to suffer from depression compared to participants with moderate food insecurity.

\subsection{Sensitivity analysis}

The results from the crude and adjusted logistic regression models where a cut-off score of $\geq 9$ was used to define depression were similar to the main logistic regression analysis indicating that the cut-off score did not influence the association between household food insecurity and depression (Supplementary material, Table S1).

The results from the ANCOVA, in which depression was included as a continuous outcome, indicated that participants with mild, moderate and severe food insecurity had higher depression scores compared to food secure participants (Supplementary material, Table S2). 
Table 2 Association between household food insecurity categories and depression

\begin{tabular}{|c|c|c|c|c|}
\hline & OR & \multicolumn{2}{|c|}{$95 \%$ C.I. } & $\mathrm{p}$ \\
\hline \multicolumn{5}{|l|}{ Crude model } \\
\hline Food secure & 1.00 & - & - & - \\
\hline Mild food insecurity & 1.61 & 1.39 & 1.85 & $<0.000$ \\
\hline Moderate food insecurity & 2.44 & 2.12 & 2.81 & $<0.000$ \\
\hline Severe food insecurity & 3.44 & 2.90 & 4.08 & $<0.000$ \\
\hline \multicolumn{5}{|l|}{ Adjusted model } \\
\hline Food secure & 1.00 & - & - & - \\
\hline Mild food insecurity & 1.47 & 1.27 & 1.71 & $<0.000$ \\
\hline Moderate food insecurity & 2.14 & 1.85 & 2.47 & $<0.000$ \\
\hline Severe food insecurity & 3.01 & 2.51 & 3.60 & $<0.000$ \\
\hline Gender (female) & 1.48 & 1.43 & 1.53 & $<0.000$ \\
\hline Age (years) & 1.01 & 1.00 & 1.02 & 0.001 \\
\hline SES (low) & 1.09 & 0.95 & 1.25 & 0.203 \\
\hline SES (middle) & 1.02 & 0.89 & 1.17 & 0.783 \\
\hline Area (urban) & 1.04 & 0.92 & 1.17 & 0.560 \\
\hline Hypertension (no) & 0.64 & 0.55 & 0.72 & $<0.000$ \\
\hline Diabetes (no) & 0.77 & 0.66 & 0.90 & 0.001 \\
\hline Education (no) & 1.46 & 1.20 & 1.79 & $<0.000$ \\
\hline Education (middle) & 1.32 & 1.15 & 1.51 & $<0.000$ \\
\hline Partner (no) & 0.90 & 0.80 & 1.01 & 0.072 \\
\hline BMI underweight & 0.89 & 0.58 & 1.35 & 0.573 \\
\hline BMI overweight & 0.91 & 0.80 & 1.02 & 0.103 \\
\hline BMI obese & 1.09 & 0.96 & 1.24 & 0.176 \\
\hline
\end{tabular}

$B M I$ body mass index (BMI normal is the reference category), OR Odds ratio, $95 \%$ CI 95\% confidence interval, SES Socioeconomic status

\section{Discussion}

This study explored the relationship between household food insecurity and depression in Mexico. Only $27 \%$ of the households were food secure. We found that household food insecurity was strongly associated with depression, and that more severe food insecurity was related to a higher depressive symptoms score.

The findings of this study are in line with previous studies evaluating the relationship between household food insecurity and mental health in different populations. For instance in Canada, Tarasuk et al. (2013) found that food insecurity severity had a dose-response relationship with mood disorders, and particularly that the odds of having a mood disorder were 1.8 higher amongst individuals living in a food insecure household. A representative survey of South Korea demonstrated that household food insecurity was related to perceived stress, depressive symptoms and suicidal ideation (Chung et al. 2016). However, it is important to stress that the rates of food insecurity in these two studies were low (12\% for Canada and $8 \%$ for South Korea) as compared to Mexico (73\%). Similarly to the Latin American and Caribbean Food Security Scale (ELCSA) used in our study, the food security scales used in these two studies were culturally adapted scales from U.S. Household Food Security/Hunger Survey (Carlson et al. 1999). However, we used CESD-SF to measure depression, but neither of the studies above used a validated questionnaire to measure depressive symptoms.

One of the proposed mechanisms underlying the association between food insecurity and depression is the effect of depression on employment status and work capabilities (Lerner and Henke 2008). Depression has been found to influence the individual's ability to obtain and retain employment, particularly for individuals with lower education (Dooley et al. 2000; Krol et al. 2011; Lennon et al. 2001). In addition, depressed individuals have higher rates of absenteeism and reduced work performance (Lerner and Henke 2008; Whooley et al. 2002; Olesen et al. 2012). This is particularly important in the context of Mexico, where more than 34\% of the population was informally employed in 2012 (Cervantes and Acharya 2013). In this type of employment, only the worked hours are paid (Niño and Hernández 2012). This in turn, may have an impact on the family's income and the ability to supply food for the household (Rose 1999).

Apart from the effect depression has on work status, income and food security, food security has also been reported to cause mental health distress in previous longitudinal studies (Huddleston-Casas et al. 2009). For instance, a study investigating the Mexican migrating population in the US found that adults who were not able to supply sufficient food for the family were more likely to have higher stress and anxiety (Hovey and Magaña 2002b; a). In another study, adolescents living in a food insecure household were more likely to have dysthymia, thoughts of death, a desire to die and have attempted suicide (Alaimo et al. 2002). It therefore appears that there is a bi-directional causal relationship between
Table 3 Differences in likelihood of being depressed between the different household food insecurity categories (OR and 95\% CI)

\begin{tabular}{lccc}
\hline Reference/Comparator & Mild food insecurity $^{\mathrm{a}}$ & Moderate food insecurity $^{\mathrm{a}}$ & Severe food insecurity $^{\mathrm{a}}$ \\
\hline Food secure $^{\mathrm{a}}$ & $1.47(1.27 \text { to } 1.71)^{* * * *}$ & $2.14(1.85 \text { to } 2.47)^{* * * *}$ & $3.01(2.51 \text { to } 3.60)^{* * * *}$ \\
Mild food insecurity $^{\mathrm{a}}$ & - & $1.45(1.28 \text { to } 1.64)^{* * * *}$ & $2.04(1.76 \text { to } 2.37)^{* * * *}$ \\
Moderate food insecurity $^{\mathrm{a}}$ & - & - & $1.41(1.21 \text { to } 1.65)^{* * *}$ \\
\hline$* * * p=<0.000$ & & \\
${ }^{\mathrm{a}}$ Depression is the dependent variable in the different regression models
\end{tabular}


household food insecurity and depression. However, the design of the present study did not allow for causal inferences.

The results of the comparison between household food security categories showed that individuals living in a household with severe food security were 1.4 times more likely to be depressed than those living in a household with moderate food insecurity, and twice more likely than those living in household with mild food security. Considering that $12 \%$ (approximately 14.5 millions) of the Mexican population lives in a household with severe food insecurity and $20 \%$ in a household with moderate food insecurity (24 millions), even a small improvement in household food insecurity could have substantial benefits in terms of mental health, depression symptomatology and quality of life of the individuals as suggested by longitudinal studies (Bronte-Tinkew et al. 2007; Kim and Frongillo 2007).

Additional clinical and demographic characteristics included in the analyses were related to depression. Participants with a diagnosis of type II diabetes or hypertension were more likely to suffer from higher depressive symptoms. Similarly, lower education was associated with higher risk for depression. Previous studies have also found a link between diabetes, hypertension, and depression (Mezuk et al. 2008; Rubio-Guerra et al. 2013), as well as a protective effect of higher education against depression (Bjelland et al. 2008). It seems therefore useful to include those clinical and demographic characteristics as covariates when different links to depression are examined.

\subsection{Strengths and limitations of the study}

One of the strengths of this study is the large sample size included, which is representative for Mexican population. Moreover, household food insecurity was operationalized using the ELCSA scale, which has been validated for the Mexican population (de la ELCSA 2012). Finally, the study investigated two highly prevalent conditions in the Mexican population (depression and food insecurity) that are very relevant considering their large burden for the Mexican society.

A number of limitations of this study need to be considered too. First, the cross-sectional design of the study does not allow drawing any conclusions on the causality direction between food security and depression, i.e., whether food (in) security determines the state of mental health, or whether mental health determines the state of food (in)security. Future longitudinal studies in Mexico are required to address this causation issue. Second, depression was operationalized using a self-report scale. Individuals were therefore not formally diagnosed with depression, which requires a structured clinical interview for its detection. However, the CESD-SF has good psychometric properties and is widely used to assess depressive symptom severity in epidemiological studies (McKellar et al. 2004). We performed two sensitivity analyses using two different operationalization of depression (a CESDSF cut-off score greater than 9, and the CESD-SF score as continuous outcome), which led to results similar to those of the main analysis. This suggests that the choice of threshold for depression did not influence this study's conclusions.

\subsection{Implications}

More than $70 \%$ of the Mexican population lives in a household experiencing at least mild food insecurity. Considering the impact that food insecurity has on the quality of life, the development and health during childhood, as well as the association with depression found in this study, this work underlines food security as a major health and societal concern. This concern is reflected in the multiple attempts of different Mexican governments to tackle food insecurity, with projects such as "Progresa" in 1997, "Oportunidades" (2006-2012), and "Prospera" and "Campaña contra el hambre" in 2012, which generally aimed to eradicate hunger. Since the success of these projects remains questionable (Behrman and Parker 2011; Ordóñez-Barba and Silva-Hernández 2019), it is urgent to develop intersectoral social programs (Shamah-Levy, Mundo-Rosas, Flores-De la Vega, \& Luiselli-Fernández, 2017) or community based interventions (Nsabuwera et al. 2016; Breckwich Vásquez et al. 2007; Alarcão et al. 2020) to provide the vulnerable population the means to obtain sufficient and quality food for their households.

The results from the current study demonstrated that, parallel to fighting hunger, it is necessary to recognize that these populations may be also vulnerable to mental health problems.

\subsection{Conclusion}

This paper provides an overview of the complex problem of food insecurity and mental health. Despite the unknown causality of the relationship, the analysis suggests a strong association between depression and food insecurity. This problem calls for much more attention from the scientific community. Given the high prevalence of depression and the alarming prevalence of household food insecurity in Mexico, the implementation of successful public health programs to improve food security is necessary.

\section{Compliance with ethical standards}

Conflict of interest The authors declare no conflict of interest.

Open Access This article is licensed under a Creative Commons Attribution 4.0 International License, which permits use, sharing, adaptation, distribution and reproduction in any medium or format, as long as you give appropriate credit to the original author(s) and the source, provide a link to the Creative Commons licence, and indicate if changes were made. The images or other third party material in this article are included in the article's Creative Commons licence, unless indicated otherwise in a credit line to the material. If material is not included in the article's Creative Commons licence and your intended use is not permitted by statutory regulation or exceeds the permitted use, you will need to obtain permission directly from the copyright holder. To view a copy of this licence, visit http://creativecommons.org/licenses/by/4.0/. 


\section{References}

Alaimo, K., Olson, C. M., \& Frongillo, E. A. (2002). Family food insufficiency, but not low family income, is positively associated with dysthymia and suicide symptoms in adolescents. The Journal of Nutrition, 132(4), 719-725.

Alarcão, V., Guiomar, S., Oliveira, A., Severo, M., Correia, D., Torres, D., et al. (2020). Food insecurity and social determinants of health among immigrants and natives in Portugal. Food Security, 1-11.

Barquera, S., Campos-Nonato, I., Hernández-Barrera, L., Pedroza, A., \& Rivera-Dommarco, J. A. (2013). Prevalence of obesity in Mexican adults 2000-2012. Salud publica de Mexico, 55, S151-S160.

Behrman, J., \& Parker, S. (2011). The impact of the PROGRESA/ Oportunidades conditional cash transfer program on health and related outcomes for the aging in Mexico.

Berlim, M., \& Fleck, M. A. (2007). Quality of life and major depression. In M. Ritsner, \& A. G. Awad (Eds.), Quality of Life Impairment in Schizophrenia, Mood and Anxiety Disorders (pp. 241-252). Springer Netherlands. doi:https://doi.org/10.1007/978-1-40205779-3 12.

Bjelland, I., Krokstad, S., Mykletun, A., Dahl, A. A., Tell, G. S., \& Tambs, K. (2008). Does a higher educational level protect against anxiety and depression? The HUNT study. Social Science \& Medicine, 66(6), 1334-1345. https://doi.org/10.1016/j.socscimed. 2007.12.019.

Breckwich Vásquez, V., Lanza, D., Hennessey-Lavery, S., Facente, S., Halpin, H. A., \& Minkler, M. (2007). Addressing food security through public policy action in a community-based participatory research partnership. Health Promotion Practice, 8(4), 342-349.

Bronte-Tinkew, J., Zaslow, M., Capps, R., Horowitz, A., \& McNamara, M. (2007). Food insecurity works through depression, parenting, and infant feeding to influence overweight and health in toddlers. The Journal of Nutrition, 137(9), 2160-2165.

Carlson, S. J., Andrews, M. S., \& Bickel, G. W. (1999). Measuring food insecurity and hunger in the United States: Development of a national benchmark measure and prevalence estimates. The Journal of Nutrition, 129(2), 510S-516S.

Cervantes, J. J., \& Acharya, A. K. (2013). La economía formal e informal en México 1995-2012: Implicaciones para los mercados laborales. Gaceta Laboral, 19(2).

Charlson, F., Erskine, H., Ferrari, A., Gouda, H., Knibbs, L., McGrath, J. J., et al. (2015). Global, regional, and national incidence, prevalence, and years lived with disability for 301 acute and chronic diseases and injuries in 188 countries, 1990-2013: A systematic analysis for the global burden of disease study 2013. The Lancet, 386(9995), 743-800.

Che, J., \& Chen, J. (2001). Food insecurity in Canadian households. Health Rep, 12(4), 11-22.

Chung, H.-K., Kim, O. Y., Kwak, S. Y., Cho, Y., Lee, K. W., \& Shin, M.J. (2016). Household food insecurity is associated with adverse mental health indicators and lower quality of life among Koreans: Results from the Korea National Health and nutrition examination survey 2012-2013. Nutrients, 8(12), 819.

de la ELCSA, C. C. (2012). Escala Latinoamericana y Caribeña de Seguridad Alimentaria (ELCSA): Manual de uso y aplicaciones. Roma: FAO.

Dewing, S., Tomlinson, M., le Roux, I. M., Chopra, M., \& Tsai, A. C. (2013). Food insecurity and its association with co-occurring postnatal depression, hazardous drinking, and suicidality among women in peri-urban South Africa. Journal of affective disorders, 150(2), 460-465.

Dooley, D., Prause, J., \& Ham-Rowbottom, K. A. (2000). Underemployment and depression: Longitudinal relationships. Journal of Health and Social Behavior, 421-436.
Fischer, N. C., Shamah-Levy, T., Mundo-Rosas, V., Méndez-GómezHumarán, I., \& Pérez-Escamilla, R. (2014). Household food insecurity is associated with anemia in adult mexican women of reproductive age. The Journal of Nutrition, 144(12), 2066-2072.

Friedenreich, C. M. (1993). Methods for pooled analyses of epidemiologic studies. Epidemiology, 295-302.

Fuller-Thomson, E., \& Nimigon, J. (2008). Factors associated with depression among individuals with chronic fatigue syndrome: findings from a nationally representative survey. Family Practice, 25(6), 414422. doi:10.1093/fampra/cmn064

Gutierrez, J., Rivera-Dommarco, J., Shamah-Levy, T., VillalpandoHernandez, S., Franco, A., Cuevas-Nasu, L., et al. (2012). Encuesta Nacional de Salud y Nutrición 2012. ResultadosNacionales. Cuernavaca, México: Instituto Nacional de Salud Pública (MX)

Hadley, C., \& Patil, C. L. (2006). Food insecurity in rural Tanzania is associated with maternal anxiety and depression. American Journal of Human Biology: The Official Journal of the Human Biology Association, 18(3), 359-368.

Hasin, D. S., Goodwin, R. D., Stinson, F. S., \& Grant, B. F. (2005). Epidemiology of major depressive disorder: Results from the National Epidemiologic Survey on alcoholism and related conditions. Archives of General Psychiatry, 62(10), 1097-1106. https:// doi.org/10.1001/archpsyc.62.10.1097.

Hovey, J. D., \& Magaña, C. G. (2002a). Cognitive, affective, and physiological expressions of anxiety symptomatology among Mexican migrant farmworkers: Predictors and generational differences. Community Mental Health Journal, 38(3), 223-237.

Hovey, J. D., \& Magaña, C. G. (2002b). Psychosocial predictors of anxiety among immigrant Mexican migrant farmworkers: Implications for prevention and treatment. Cultural Diversity and Ethnic Minority Psychology, 8(3), 274-289.

Huddleston-Casas, C., Charnigo, R., \& Simmons, L. A. (2009). Food insecurity and maternal depression in rural, low-income families: A longitudinal investigation. Public Health Nutrition, 12(8), 11331140 .

IsHak, W. W., Greenberg, J. M., Balayan, K., Kapitanski, N., Jeffrey, J., Fathy, H., et al. (2011). Quality of life: The ultimate outcome measure of interventions in major depressive disorder. Harvard Review of Psychiatry, 19(5), 229-239. https://doi.org/10.3109/10673229. 2011.614099.

Jones, A. D. (2017). Food insecurity and mental health status: A global analysis of 149 countries. American Journal of Preventive Medicine.

Jones, A. D., Ngure, F. M., Pelto, G., \& Young, S. L. (2013). What are we assessing when we measure food security? A compendium and review of current metrics. Advances in Nutrition: An International Review Journal, 4(5), 481-505.

Kassebaum, N. J., Arora, M., Barber, R. M., Bhutta, Z. A., Brown, J., Carter, A., et al. (2016). Global, regional, and national disabilityadjusted life-years (DALYs) for 315 diseases and injuries and healthy life expectancy (HALE), 1990-2015: A systematic analysis for the global burden of disease study 2015. The Lancet, 388(10053), 1603-1658.

Kim, K., \& Frongillo, E. A. (2007). Participation in food assistance programs modifies the relation of food insecurity with weight and depression in elders. The Journal of Nutrition, 137(4), 1005-1010.

Kolovos, S., Bosmans, J. E., van Dongen, J. M., van Esveld, B., Magai, D., van Straten, A., et al. (2017). Utility scores for different health states related to depression: Individual participant data analysis. Quality of Life Research, 26, 1649-1658. https://doi.org/10.1007/ s11136-017-1536-2.

Krol, M., Papenburg, J., Koopmanschap, M., \& Brouwer, W. (2011). Do productivity costs matter? The impact of including productivity costs on the incremental costs of interventions targeted at depressive disorders. PharmacoEconomics, 29(7), 601-619. http://search. 
ebscohost.com/login. asp $x$ ?direct=true $\& d b=$ psyh $\& A N=2011$ 13069-005\&site=ehost-live krol@bmg.eur.nl.

Kupfer, D. J., \& Frank, E. (2003). Comorbidity in depression. Acta Psychiatrica Scandinavica. Supplementum, 418, 57-60.

Lennon, M. C., Blome, J., \& English, K. (2001) 'Depression and lowincome women: Challenges for TANF and welfare-to-work policies and programs'. Research forum on children, families, and the new federalism, National Center for children in poverty, mailman School of Public Health, Columbia University.

Lerner, D., \& Henke, R. M. (2008). What does research tell us about depression, job performance, and work productivity? Journal of Occupational and Environmental Medicine, 50(4), 401-410.

Levine, S. Z. (2013). Evaluating the seven-item Center for Epidemiologic Studies depression scale short-form: A longitudinal U.S. community study. Social Psychiatry and Psychiatric Epidemiology, 48(9), 1519-1526. https://doi.org/10.1007/s00127-012-0650-2.

Li, F., Bai, X., \& Wang, Y. (2013). The scale of positive and negative experience (SPANE): Psychometric properties and normative data in a large Chinese sample. PLoS One, 8(4), e61137.

Maxwell, S. (1996). Food security: A post-modern perspective. Food Policy, 21(2), 155-170. https://doi.org/10.1016/0306-9192(95) 00074-7.

McKellar, J. D., Humphreys, K., \& Piette, J. D. (2004). Depression increases diabetes symptoms by complicating patients' self-care adherence. The Diabetes Educator, 30(3), 485-492.

Mendenhall, E., Kohrt, B. A., Norris, S. A., Ndetei, D., \& Prabhakaran, D. (2017). Non-communicable disease syndemics: Poverty, depression, and diabetes among low-income populations. The Lancet, 389(10072), 951-963.

Mezuk, B., Eaton, W. W., Albrecht, S., \& Golden, S. H. (2008). Depression and type 2 diabetes over the lifespan: A meta-analysis. Diabetes Care, 31(12), 2383-2390. https://doi.org/10.2337/dc080985.

Morales-Ruan Mdel, C., Mendez-Gomez Humaran, I., Shamah-Levy, T., Valderrama-Alvarez, Z., \& Melgar-Quinonez, H. (2014). [food insecurity is associated with obesity in adult women of Mexico]. Salud Publica Mex, 56 Suppl 1, s54-61.

Niño, J. J. C., \& Hernández, L. P. (2012). El trabajo en la pepena informal en México: nuevas realidades, nuevas desigualdades. Estudios demográficos y Urbanos, 95-117.

Nsabuwera, V., Hedt-Gauthier, B., Khogali, M., Edginton, M., Hinderaker, S. G., Nisingizwe, M. P., Tihabyona Jde, D., Sikubwabo, B., Sembagare, S., Habinshuti, A., \& Drobac, P. (2016). Making progress towards food security: Evidence from an intervention in three rural districts of Rwanda. Public Health Nutrition, 19(7), 1296-1304.

Olesen, J., Gustavsson, A., Svensson, M., Wittchen, H. U., \& Jonsson, B. (2012). The economic cost of brain disorders in Europe. European Journal of Neurology, 19(1), 155-162. https://doi.org/10.1111/j. 1468-1331.2011.03590.x.

Ordóñez-Barba, G. M., \& Silva-Hernández, A. L. (2019). ProgresaOportunidades-Prospera: avatares, alcances y resultados de un programa paradigmático contra la pobreza. Papeles de Población, 25(99), 77-112.

Pérez-Escamilla, R., Villalpando, S., Shamah-Levy, T., \& MéndezGómez Humarán, I. (2014). Household food insecurity, diabetes and hypertension among Mexican adults: Results from Ensanut 2012. salud pública de méxico, 56, s62-s70.

Power, M., Uphoff, E., Kelly, B., \& Pickett, K. E. (2017). Food insecurity and mental health: An analysis of routine primary care data of pregnant women in the born in Bradford cohort. Journal of
Epidemiology and Community Health, 71(4), 324-328. https://doi. org/10.1136/jech-2016-207799.

Romero-Martínez, M., Shamah-Levy, T., Franco-Núñez, A., Villalpando, S., Cuevas-Nasu, L., Gutiérrez, J. P., et al. (2013). Encuesta Nacional de Salud y Nutrición 2012: diseño y cobertura. salud pública de méxico, 55, S332-S340.

Romo-Aviles, M., \& Ortiz-Hernández, L. (2018). Energy and nutrient supply according to food insecurity severity among Mexican households. Food Security, 10(5), 1163-1172.

Rose-Jacobs, R., Black, M. M., Casey, P. H., Cook, J. T., Cutts, D. B., Chilton, M., Heeren, T., Levenson, S. M., Meyers, A. F., \& Frank, D. A. (2008). Household food insecurity: Associations with at-risk infant and toddler development. Pediatrics, 121(1), 65-72.

Rose, D. (1999). Economic determinants and dietary consequences of food insecurity in the United States. The Journal of Nutrition, 129(2), 517S-520S.

Rubio-Guerra, A. F., Rodriguez-Lopez, L., Vargas-Ayala, G., HuertaRamirez, S., Serna, D. C., \& Lozano-Nuevo, J. J. (2013). Depression increases the risk for uncontrolled hypertension. Experimental and Clinical Cardiology, 18(1), 10-12. https://www. ncbi.nlm.nih.gov/pubmed/24294029, https://www.ncbi.nlm.nih. gov/pmc/articles/PMC3716493/.

Seligman, H. K., Laraia, B. A., \& Kushel, M. B. (2010). Food insecurity is associated with chronic disease among low-income NHANES participants. The Journal of Nutrition, 140(2), 304-310.

Sharma, P., \& Gulati, A. (2015) 'Approaches to food security in Brazil, China, India, Malaysia, Mexico, and Nigeria: lessons for developing countries'.

Slone, L. B., Norris, F. H., Murphy, A. D., Baker, C. K., Perilla, J. L., Diaz, D., Rodriguez, F. G., \& Gutiérrez Rodriguez Jde, J. (2006). Epidemiology of major depression in four cities in Mexico. Depression and Anxiety, 23(3), 158-167.

Stuff, J. E., Casey, P. H., Szeto, K. L., Gossett, J. M., Robbins, J. M., Simpson, P. M., .. . Bogle, M. L. (2004). Household food insecurity is associated with adult health status. The Journal of nutrition, 134(9), 2330-2335

Tarasuk, V., Mitchell, A., McLaren, L., \& McIntyre, L. (2013). Chronic physical and mental health conditions among adults may increase vulnerability to household food insecurity. The Journal of nutrition, jn., 113(178483).

Trefry, A., Parkins, J. R., \& Cundill, G. (2014). Culture and food security: A case study of homestead food production in South Africa. Food security, 6(4), 555-565.

Vos, T., Allen, C., Arora, M., Barber, R. M., Bhutta, Z. A., Brown, A., et al. (2016). Global, regional, and national incidence, prevalence, and years lived with disability for 310 diseases and injuries, 19902015: A systematic analysis for the global burden of disease study 2015. The Lancet, 388(10053), 1545-1602.

Whooley, M. A., Kiefe, C. I., Chesney, M. A., Markovitz, J. H., Matthews, K., \& Hulley, S. B. (2002). Depressive symptoms, unemployment, and loss of income: The CARDIA study. Archives of Internal Medicine, 162(22), 2614-2620.

Wittchen, H. U., Jacobi, F., Rehm, J., Gustavsson, A., Svensson, M., Jonsson, B., et al. (2011). The size and burden of mental disorders and other disorders of the brain in Europe 2010. European Neuropsychopharmacology, 21(9), 655-679. https://doi.org/10. 1016/j.euroneuro.2011.07.018.

Zavala, G. A., Kolovos, S., Chiarotto, A., Bosmans, J. E., Campos-Ponce, M., Rosado, J. L., \& Garcia, O. P. (2018a). Association between obesity and depressive symptoms in Mexican population. Social 
Psychiatry and Psychiatric Epidemiology, 53(6), 639-646. https:// doi.org/10.1007/s00127-018-1517-y.

Zavala, G. A., Kolovos, S., Chiarotto, A., Bosmans, J. E., Campos-Ponce, M., Rosado, J. L., \& Garcia, O. P. (2018b). Association between obesity and depressive symptoms in Mexican population. Social Psychiatry and Psychiatric Epidemiology, 53(6), 639-646.

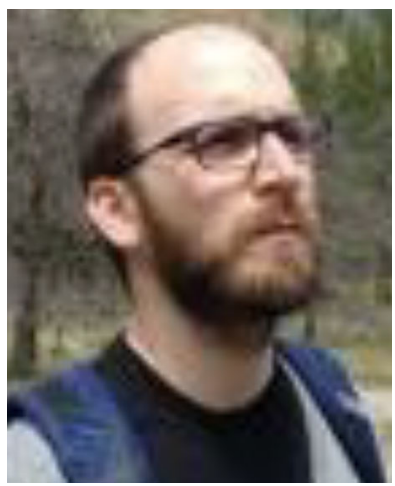

Spyros Kolovos studied Psychology at the National and Kapodistrian University of Athens. He obtained a research MSc in Clinical and Developmental Psychopathology in VU Amsterdam. As a PhD student at the Health Sciences Department of VU Amsterdam, he investigated the changes in quality of life of patients with depression, and examined the costeffectiveness of Internet-based treatments for depression. He was involved in meta-analyses, as well as trial-based and model-based economic evaluations. He currently holds a post-doc position as a health economist in the Nuffield Department of Orthopaedics, Rheumatology and Musculoskeletal Sciences, in the University of Oxford.

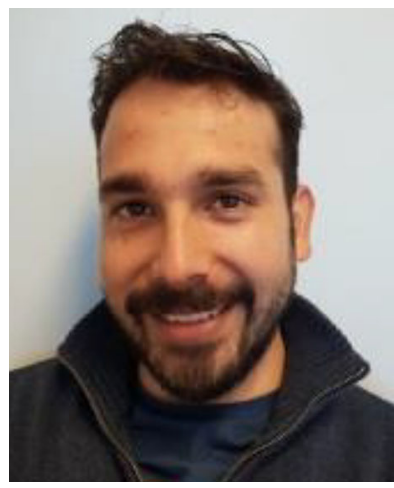

Gerardo A Zavala was born on the 19th of May 1984 in the Mexican city of Queretaro. He completed a bachelor degree in chemistry with a specialization in food chemistry at the Universidad Autonoma de Queretaro. As part of his studies he completed an internship at the University of Santiago de Compostela in Spain. After he decided to study further and completed a Master's degree in human nutrition and proudly graduated cum laude. During his master he did an internship at the school of public health in the University of Queensland Australia, studying the relationship between inflammatory markers and the concentration of micronutrients in human population (research that was published in a peer reviewed journal). Afterwards, he got a $\mathrm{PhD}$ fellowship funded by the Consejo Nacional de Ciencia y Tecnologia (CONACyT) de Mexico to complete his PhD at the department of Health Sciences at the Vrije Universiteit Amsterdam. In parallel to his $\mathrm{PhD}$ research project, Gerardo has completed different courses in epidemiology. To this day Gerardo is still committed to the topic of nutrition and health and he aims to continue developing in this field with promising plans for the near future.

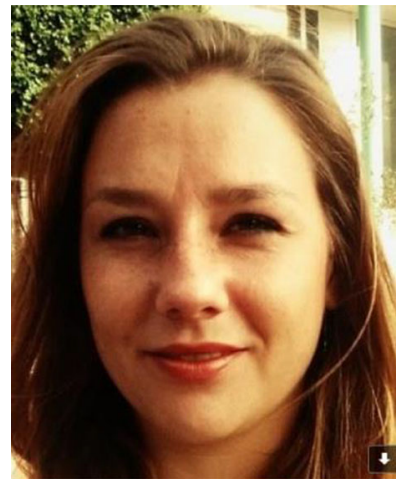

Anne Sophie Leijen studied a Bachelor in health sciences and a Master degree in health sciences at the Vrije Universitait Amsterdam. There she worked together with Spyros Kolovos and Gerardo Zavala in the project: Relationship between food security and depression in Mexico

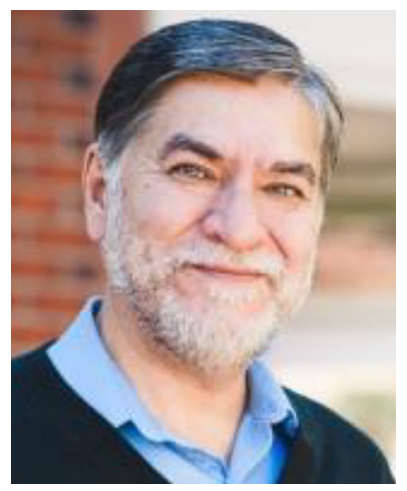

Dr. Melgar-Quiñonez is the Director of the Institute for Global Food Security and the Margaret A. Gilliam Faculty Scholar in Food Security with an appointment in the McGill School of Dietetics and Human Nutrition. With a degree in Medicine (1992) and a doctoral degree in Science $\mathrm{s}$ (1996) from the Friedrich Schiller University in Germany, he moved to McGill in September of 2012, after 9 years of work as a professor in the Department of Nutrition at the Ohio State University (2003-2012). Previously he worked in public health nutrition and food security research at the University of California in Davis (1998-2003) and at the Mexican Institute of Public Health (1996-1998). Dr. MelgarQuiñonez has been a food security advisor on to several countries in Latin America. He has conducted food security research in 20 countries in Africa, Asia and the Americas, and maintains a strong collaboration with the United Nations Food and Agriculture Organization (FAO) as a researcher in the project Voices of the Hungry which incorporates 150 countries. 


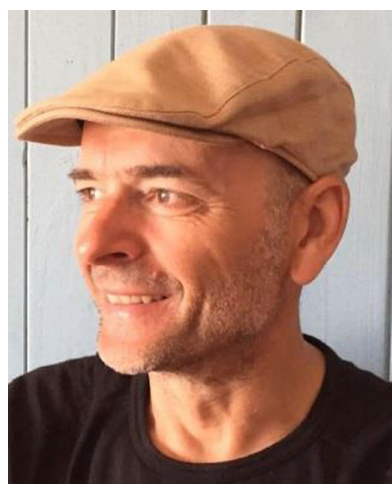

Maurits van Tulder is a full professor of Health Technology Assessment at the Department of Health Sciences of the VU University $(90 \%)$ and the Department of Epidemiology and Biostatistics of the VU University Medical Center (10\%) in Amsterdam. In 2002, he spent a sabbatical at the Institute for Work \& Health (IWH) in Toronto, Canada, where he still has a position as adjunct scientist. Maurits (co) authored more than 250 scientific publications in international peer reviewed journals on randomized controlled trials, systematic reviews, clinical guidelines and economic evaluations, especially in the field of musculoskeletal disorders. He is also author of several national publications, book chapters and a book on evidence-based practice for low back pain. His main research interest is in effectiveness and costeffectiveness of preventive and therapeutic interventions for chronic diseases. He has been member of various national and international guideline committees and chairman of the COST B13 European Guidelines for the Management of Low Back Pain. Currently he is co-editor of the Cochrane Back Review Group and Deputy Editor of the European Spine Journal. 